\title{
Percepção local sobre política pública de saneamento do Rio Carahá na cidade de Lages/SC: um estudo preliminar
}

Lages é uma importante cidade do Planalto Catarinense, que vem realizando esforços no sentido de melhorar sua estrutura de tratamento de esgoto. Entretanto um de seus rios, o Carahá, que corta a região mais densamente ocupada do município, recebe efluentes em diversos pontos e é percebido pela população local mais como um canal de esgoto do que como um rio. O presente artigo apresenta uma pesquisa exploratória que identificou a percepção atual da comunidade residente no entorno do Rio Carahá sobre ações e políticas públicas municipais na esfera de saneamento com o objetivo de embasar estudos mais aprofundados no futuro.

Palavras-chave: Saneamento; Percepção; Poluição; Rio Carahá.

\section{Local perception about the public sanitation policy of the Carahá River in the city of Lages/SC: a preliminary study}

Lages is an important city in the Plateau of the State of Santa Catarina, which has been making efforts to improve its sewage treatment structure. However, one of its rivers, the Carahá, which runs through the most densely occupied region of the municipality, receives waste at various points and is perceived by the local population more as a sewer channel than a river. This paper presents an exploratory research out which identified the current perception of the resident community nearby around the Carahá River about municipal public acting and policies in the area of sanitation, with the intention of supporting more complete studies in the future.

Keywords: Sanitation; Perception; Pollution; Carahá River.

Topic: Planejamento, Gestão e Políticas Públicas Ambientais

Reviewed anonymously in the process of blind peer.

Ronaldo Raemy Rangel

Fundação Getúlio Vargas, Brasil

http://lattes.cnpq.br/0568681030105027

http://orcid.org/0000-0003-0195-0481

rrrangel@fgvmail.br

Nathália Alonso Rangel

Escola Paulista de Negócios, Brasil

http://lattes.cnpq.br/4454175832150850

http://orcid.org/0000-0002-2229-4279

nathaliaalonsoadv@yahoo.com.br
Received: 05/03/2020

Approved: $24 / 06 / 2020$
Referencing this:

RANGEL, R. R.; RANGEL, N. A.. Percepção local sobre política pública de saneamento do Rio Carahá na cidade de Lages/SC: um estudo preliminar. Natural Resources, v.10, n.2, p.76-85, 2020. DOI: http://doi.org/10.6008/CBPC2237-9290.2020.002.0010 


\section{INTRODUÇÃO}

No site da Prefeitura de Lages está disponível um artigo que afirma que o município realizou expressivos investimentos nos últimos três anos e será, em breve, referência estadual no tratamento adequado de esgoto (TIVES, 2019). Entretanto estudos anteriores e independentes sobre o tema, apontam para certa contradição sobre essa informação, principalmente quanto a abrangência da rede coletora de esgoto que atende a área urbana - da cidade.

Destaque-se que o município de Lages é localizado em região de recarga de aquífero e mantém Áreas de Preservação Permanente (APP), principalmente de vegetação ripária (ou ribeirinha), porém segundo o Censo Demográfico (IBGE, 2010), no início da década de 2010, somente 54,6\% dos seus domicílios tinham acesso à rede de esgoto.

A par do percentual citado estar acima da média nacional e da existência de Plano Diretor de Desenvolvimento Territorial de Lages (estabelecido pela Lei Complementar 523/2018), do município contar com uma Secretaria Municipal específica para águas e saneamento e, de haver um Plano Diretor e Saneamento Ambiental para a cidade, aparentemente a questão da destinação correta dos resíduos de esgoto necessita de um maior envolvimento dos órgãos públicos municipais, vez que, estudos apontam que, a comunidade local, embora ciente da importância do saneamento básico não percebe melhora na condição de tal serviço (ANTUNES et al., 2014).

Vale lembrar que diferente de opinião, a percepção está associada ao contato com elementos que, coletivos ou individuais, objetivos ou subjetivo, expressam alguma experiência.

O fato de a subjetividade referir-se àquilo que é único e singular do sujeito não significa que sua gênese esteja no interior do indivíduo. A gênese dessa parcialidade está justamente nas relações sociais do indivíduo, quando ele se apropria (ou subjetiva) de tais relações de forma única. (SILVA, 2009).

Sabe-se que os princípios que norteiam o Plano Diretor do município são determinados pelo Estatuto da Cidade (Lei 10.257/01) que estabelece diretrizes gerais para política urbana nacional. Assim, todo Plano Diretor é tratado como o instrumento básico para orientar o desenvolvimento socioambiental e urbano do município. Entretanto, para que o Plano Diretor desempenhe sua função, os setores do governo municipal devem enfrentar e vencer o grande desafio de engajar o munícipe, fazendo-o compreender e confiar de que as interferências no espaço e nos aparelhos urbanos atenderão demandas presentes, assim como vão assegurar às futuras gerações um padrão de adequado de qualidade de vida.

Isto é necessário, pois mesmo que de forma inconsciente, os indivíduos avaliam o estágio do bemestar não só no presente, mas também em termos de possibilidade de escolhas sobre o futuro. Assim, não basta aos governos locais instituírem formas de planejamento e controle do território, é necessário que realizem o planejamento das cidades criando espaços urbanos sustentáveis. Assim, o espaço urbano deve ser humanizado, integrado com o ecossistema e economicamente suficiente, onde pessoas 'percebam' que tem direito pleno a cidadania e que podem realizar escolhas quanto a viver, a despeito de diferenças culturais. 
Desta maneira, mesmo considerando, como certo, o esforço da prefeitura de Lages em ampliar o sistema de saneamento e de dar melhor tratamento ao esgoto da cidade, a causa do gap entre a ação governamental e a percepção popular sobre tal ação pode ser utilizada como um dos critérios de avaliação das atuais condições das políticas públicas municipais, não só em termos de eficácia observada pela comunidade local no que tange ao saneamento mas, por extrapolação, sobre diversas outras áreas abrangidas pela política realizada quanto a identificação e, principalmente, compreensão sobre tais esforços e suas consequências positivas

Entender a percepção do munícipe sobre o tema disponibilizará conhecimentos úteis para a definição da política de saneamento e de outras políticas públicas e, inclusive, para o planejamento de ações de comunicação específicas sobre os aspectos desenvolvidos em tais políticas, estreitando as relações do governo com os cidadãos.

Pelo exposto, este estudo, embora preliminar, foca-se em buscar identificar instrumental para a análise da situação atual da política de saneamento em Lages/SC, pretendendo, particularmente, identificar a percepção dos lageanos quanto as condições e resultados de tal política, objetivando com isso nortear outras pesquisas. Para tanto, abrange - nesta fase inicial - tão-somente a percepção do morador local quanto a política municipal para a salubridade do Rio Carahá que corta a cidade.

\section{RELATO}

\section{Indicadores para avalição de políticas públicas}

Um dos maiores desafios, entre tantos, de um gestor público, reside em fazer com que uma série de ações de políticas públicas, conjugadas normalmente no âmbito de um planejamento, resulte em sucesso quanto aos seus objetivos. Por vezes, o planejamento tecnicamente bem elaborado deixa de atingir a meta prevista e a conclusão mais recorrente se encontra respalda ao se observar que ocorreram falhas em sua execução, atribuídas na maioria dos casos a dificuldades no processo de gestão, ou ainda à conjuntura desfavorável para implantação do plano, como por exemplo a ausência de condições materiais ou financeiras. Nessa situação, fica nítido que faltaram recursos para a execução, mas também eficiência na elaboração do planejamento no estágio de diagnóstico o qual obviamente deve identificar tanto a necessidade, quanto a disponibilidade de recursos. No caso apresentado, a implementação do planejamento não se concretizou e, portanto, os objetivos propostos eram impossíveis de serem alcançados frente aos meios disponíveis.

Por outro lado, pode ocorrer que o planejamento seja implementado em sua totalidade e executado de forma eficiente e, mesmo assim, os resultados atingidos não serem os esperados. Na hipótese apresentada deve-se questionar a capacidade de ajustar o planejamento às mudanças no ambiente em que foi praticado.

Essa situação, de dificuldade de avaliação e monitoramento do ambiente, nos recorda que as variáveis que interferem na avaliação da eficácia de um planejamento governamental são bem mais 
complexas do que os pressupostos usuais utilizados na elaboração de planos privados e empresariais por se tratar de um ambiente mais plural e, nos mais variados níveis. A correta elaboração do planejamento público não trata, ou não deveria tratar, apenas de avaliar forma ou conteúdo ou, ainda, de estimar os resultados quantitativos esperados, mas sim construir cenários sobre todas as variáveis que interagem e impactam (positiva ou negativamente) o planejado, afetando (ou, em alguns casos, impossibilitando) a obtenção dos resultados previstos.

Na década de 1970 o economista chileno Carlos Matus concebeu uma forma de planejamento estratégico o qual até hoje é considerado adequado para as necessidades do planejamento público e que chamou de Planejamento Estratégico Situacional, alertando, de pronto, que o Planejamento Situacional é uma atividade eminentemente política, e, que, portanto, precisa ser viável politicamente.

Assim sendo, Matus considerou que a eficácia do planejamento público dependia da capacidade de governar, o que para o autor dizia respeito a três variáveis que atuam concomitantemente: Projeto de Governo, Capacidade de Governo e Governabilidade (HUERTAS, 1996). Se tomarmos apenas a variável Governabilidade como elemento de interesse para o presente trabalho, somos forçados a aceitar que a eficácia do planejamento público (ou situacional) dependerá da capacidade do governo em se aproximar de aliados e ter competência para neutralizar ações de opositores.

Deste modo, seria correto afirmar que as instituições governamentais responsáveis pelo planejamento necessitam estar próximas da sociedade civil organizada, não só buscando apoio para o plano em si, mas acima de tudo, compreendendo as demandas coletivas que devem ser incorporadas na sua elaboração. Assim, torna-se indispensável para o bom desenvolvimento do planejado a construção de instrumentos apropriados para analisar, criticar e, principalmente, retro informar a comunidade quanto a eficácia dos planos ou programas de políticas públicas.

A avaliação capaz de prover o exame da qualidade do planejamento situacional (ou público), deve ao mesmo tempo considerar a performance retrospectiva e a performance futura, ou seja, deve estabelecer índices pregressos que possam ser comparados como indicadores prospectivos ou de tendência, assim como com os indicadores efetivos do que foi realizado até o estágio presente do planejamento.

Isso significa ir além dos indicadores econômicos tradicionais. Por exemplo, existe um indicador conhecido como Índice de Progresso Social (IPS) que busca avaliar a evolução social de países. O IPS combina indicadores sociais e ambientais vis-à-vis o crescimento econômico, além de identificar a percepção dos atores sociais quanto as oportunidades de desenvolvimento dos países.

Diante da iniciativa de construção de um Índice de Progresso Social, se torna justificável a tentativa de elaborar uma metodologia capaz de avaliar qualitativamente a eficácia do planejamento de políticas públicas, a serem implementadas ou já em execução, uma vez que os resultados quantitativos por meio dela obtidos podem não ser bastantes e suficientes para determinar a correção de escolhas derivadas de seu plano de ação. Assim, a percepção da sociedade, ou no mínimo do público atingido pelo plano, deve ser considerada e utilizada como um indicador. 
Evidentemente tal metodologia pode ser aplicada para os diversos níveis de governo, sendo que já há inúmeros trabalhos acadêmicos que buscam examinar a possibilidade do desenvolvimento local alicerçados na percepção da coletividade tais como: Martins et al. (2009) ou Coelho et al. (2020) e Rangel et al. (2020).

Como já anunciado, este é um dos objetivos do presente estudo: examinar a perspectiva da expansão e efetividade de políticas públicas de saneamento no município de Lages, sobre o olhar do munícipe, especificamente identificando a sua percepção quanto impacto de políticas de redução do lançamento de esgoto in natura e de outros efluentes, como possibilidade de mitigar a poluição e os danos ao Rio Carahá.

\section{DISCUSSÃO}

\section{O município de Lages em números}

Segundo o Cidade@ do IBGE (2016) Lages é a maior cidade da Região do Planalto Catarinense (a qual inclui as mesorregiões Serrana e Oeste Catarinense), sendo que o município registrou em 2016 um PIB de R\$ 4,7 bilhões (e PIB per capita de $\mathrm{R} \$ 29.930,95$.$) , montante que o colocou na 11$ ạ posição no Estado de Santa Cataria e na 194 a no país. Conforme observado no gráfico 1, o PIB municipal vem crescendo de forma consistente e constante ao longo das duas últimas décadas.

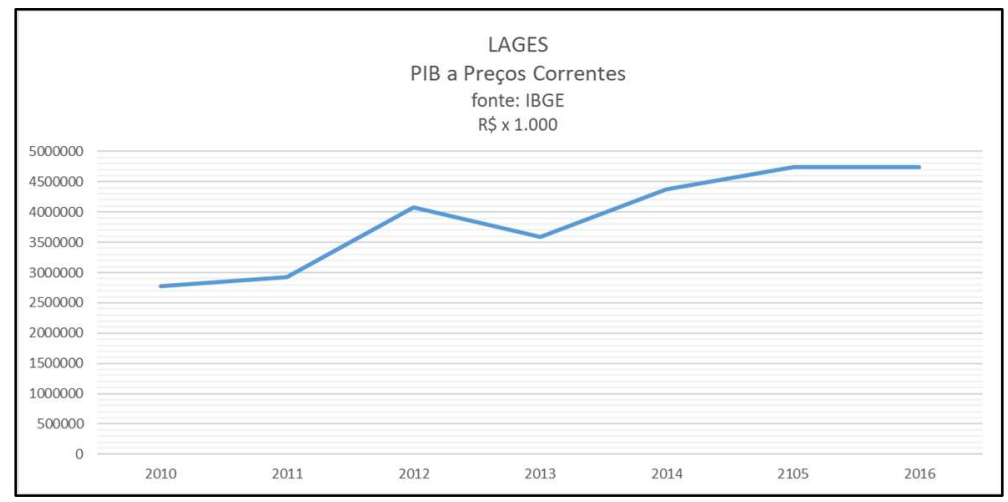

Gráfico 1: PIB a Preços Correntes. Fonte: IBGE (2016).

Descontado o valor adicionado dos impostos e da administração pública, 63,1\% do PIB municipal está associado ao setor terciário, 34,4\% ao secundário e 2,5\% ao setor primário. Destaque-se que, conforme podese verificar através do gráfico 1, no período compreendido entre 2010 e 2016, seu PIB apresentou uma taxa média de crescimento de $11,4 \%$ ao ano, muito acima da média nacional para o período.

De acordo com dados do Ministério do Trabalho e Emprego, em 2015, Lages contava com 9.079 empresas, as quais foram responsáveis pela geração de 43.053 empregos formais. Entretanto no mesmo ano, as empresas de micro e pequeno porte representavam $99,1 \%$ dos estabelecimentos presentes no município. As MPE foram responsáveis por $55,3 \%$ dos postos formais de trabalho. Do total, $41,6 \%$ dos estabelecimentos em Lages estão ligados setor de prestação de serviços, 37,7\% ao comércio, 15,4\% à indústria e 5,4\% ao setor de agropecuária.

O IDH do município era de 0,770 em 2016, o que o colocou na faixa de Desenvolvimento Humano Alto. Sua população estimada também em 2016 era de 157.544 habitantes, sendo que deste, 98,22\% 
residiam na área urbana. Confirmando aspectos eminentemente urbanos do município, dados do Departamento Estadual de Trânsito de Santa Catarina (DETRAN/SC, 2018), demonstram que entre os anos 2007 e 2017, a frota veicular no município cresceu 70,43\%. Ademais, vale ressaltar outras características fortemente urbanas de Lages. Dados do INEP afirmam que 2018 Santa Cataria possuía 207 Instituições de Ensino Superior (IES), das quais 19 em Lages, (INEP, 2018) e que o setor de prestação de serviços é o que mais emprega no município totalizando $46,2 \%$ da população ocupada.

Atualmente a cidade de Lages está consolidada como 'cidade-polo' devido ao corredor logístico que a circunda, composto por sua malha viária de rodovias que facilita o deslocamento da produção e da população de toda a região. Em verdade, a origem do município decorre de sua localização que criou a sua vocação como centro comercial regional, “cujas raízes remontam ao período do 'caminho das tropas' do século XVIII" (GARCIA, 2017).

Considerando o elevado número de pessoas que residem na área urbana, há inequívoca necessidade de infraestrutura adequada para o desenvolvimento da cidade. Pelo exposto, considera-se que um tema de alta relevância econômica-social para Lages é avaliar a qualidade da água e das condições de saneamento. $\mathrm{O}$ Rio Carahá, que com seus 7 mil metros de extensão corta o município e flui dentro da cidade, recebe carga orgânica constante que, sem tratamento adequado aumenta o volume de poluentes e, aparentemente, leva à continua degradação de suas águas. A relevância do Carahá para Lages pode ser atestada pela imagem georeferenciada abaixo:

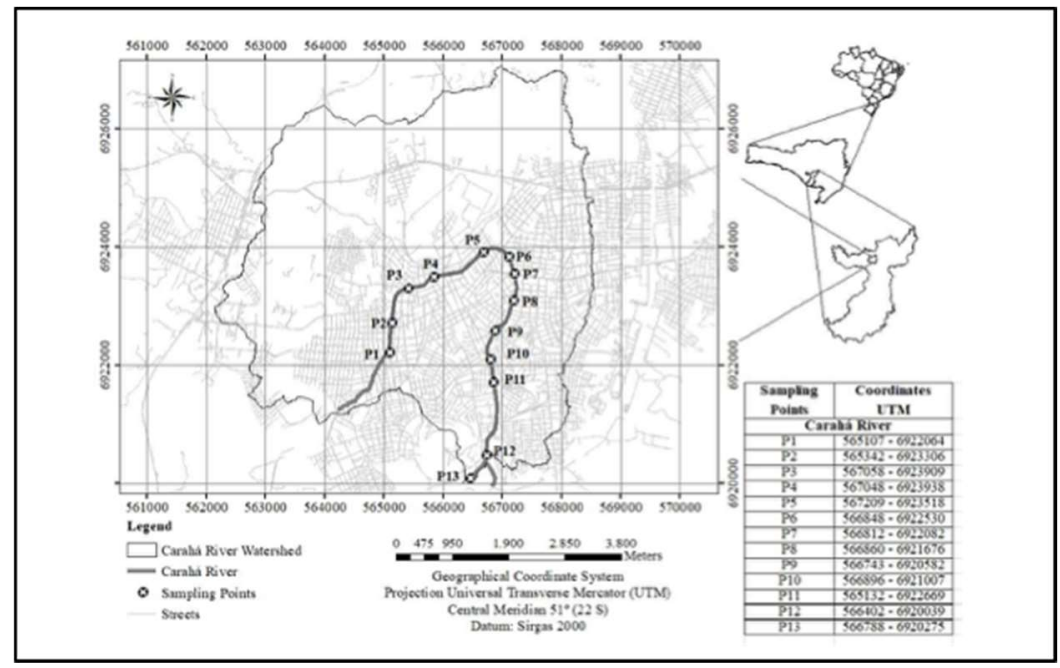

Figura 1: Geolocalização do Rio Carahá. Fonte: Quinatto et al. (2019).

A par da poluição, o Carahá frequentemente inunda, possuindo trechos considerados pela defesa civil como áreas de risco para a cidade e sua população (RAFAELI NETO et al., 2015). Em 2014 foi realizado um estudo quanto a situação do entorno do Rio Carahá (ANTUNES et al., 2014). Embora tal estudo tenha se valido da análise de parâmetros físicos e químicos das águas do rio, foi possível na pesquisa:

Perceber que os moradores têm consciência da poluição das águas na região da do Rio Carahá, embora pareça haver falta de informação sobre as consequências do contato com o rio poluído e certa aceitação (até mesmo conformista) em relação a essa situação.

O curioso em tal percepção é que o Sistema Nacional de Informações sobre Saneamento - SNIS, afirma em documento de 2019, que Lages, em 2018, possuía 84,9\% do esgotamento sanitário considerado 
adequando, ou seja, para o SNIS em Lages há um alto percentual do esgoto tratado em relação ao coletado. Muito provavelmente a aparente discrepância entre dados oficiais e a percepção do munícipe ocorra pela localização dos investimentos recentes da Secretaria Municipal de Águas e Saneamento (Semasa), principalmente com a construção dos complexos de tratamento de Araucária e Ponte Grande.

Se retomarmos o artigo de Tives (2019) publicado no site da Prefeitura de Lages, vamos verificar que os bairros beneficiados pelos recursos para tratamento de esgoto nos dois complexos são: Promorar; Santo Antônio; São Luiz; Centenário; Santa Catarina; Santa Clara; Novo Milênio e Araucária, nenhum deles tangenciados pelo Rio Carahá, que como demonstra a Figura 2, essencialmente contorna o centro da cidade, o qual, por sua vez é extremamente povoado (Figura 3).

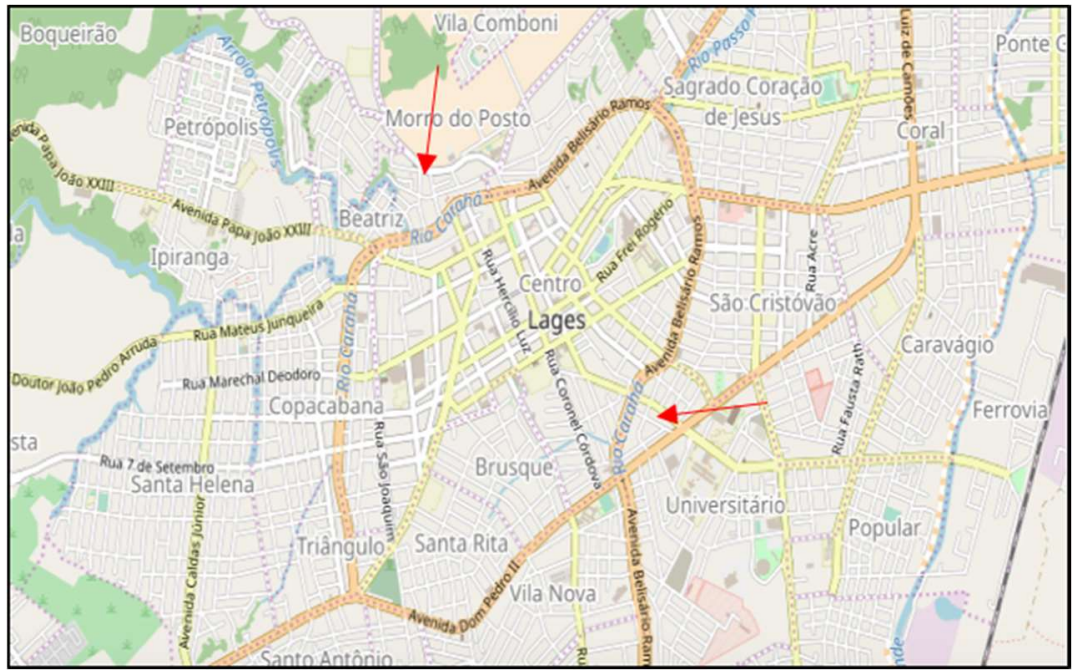

Figura 2: Rio Carahá e Centro de Lages. Fonte: Google Maps.

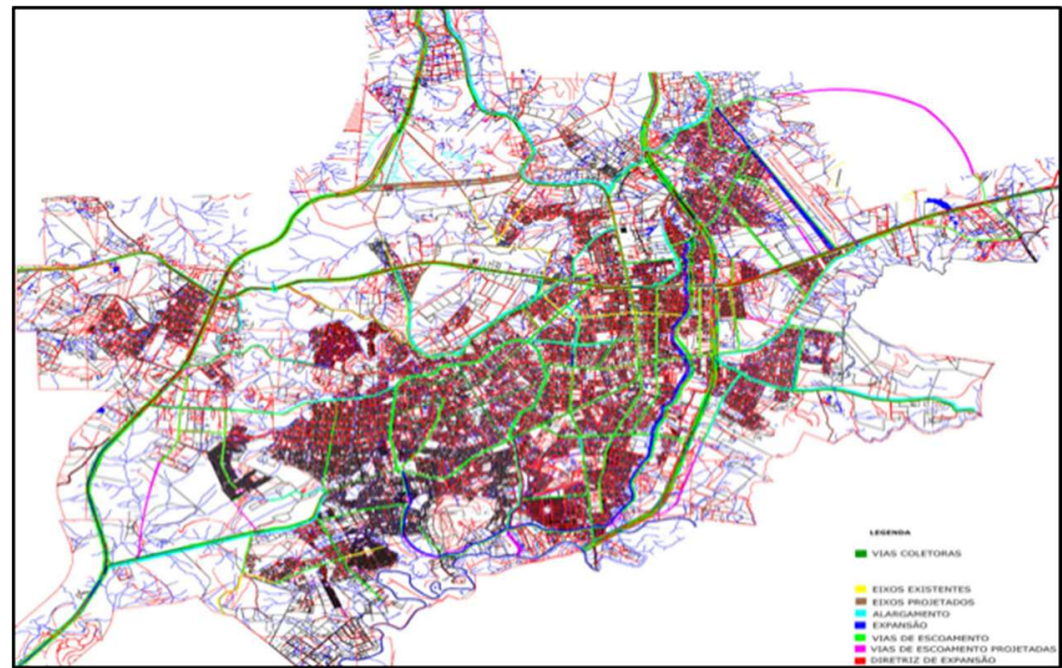

Figura 3: Concentração Urbana no Centro de Lages. Prefeitura de Lages, hierarquia viária.

Seja como for, a realidade recente do Rio Carahá era de 'água escura e com lixo em muitos pontos, dá a impressão que o rio, vindo de duas nascentes que despejam água limpa, virou esgoto a céu aberto'.

\section{Pesquisa Exploratória e seus Resultados}

Para atender ao proposto nesta fase de diagnóstico o presente trabalho, busca identificar a percepção do lageano sobre as políticas públicas de saneamento e sobre as condições de salubridade do Rio 
Carahá. Nesta direção, para a coleta de informações necessárias para esta primeira etapa, optamos pela realização prévia de uma pesquisa exploratória, a qual dará suporte a estudos mais aprofundados no futuro, pois sabe-se que a pesquisa exploratória tem "como objetivo proporcionar maior familiaridade com o problema com vistas a torna-lo mais explícito ou a construir hipóteses" (DIEHL et al., 2004) e assim sendo a etapa atual "servirá como base para pesquisas posteriores" (CASARIN et al., 2012).

Reforçando a escolha metodológica alertamos, ainda, que segundo Antônio Carlos Gil, na pesquisa exploratória "o pesquisador seleciona os elementos a que tem acesso, admitindo que estes possam, de alguma forma, representar o universo" (GIL, 2008). Assim, a pesquisa exploratória tem como uma de suas características a possibilidade de se valer de amostras pequenas e não-probabilísticas, além de manter certa informalidade na relação do pesquisador com os entrevistados, o que coaduna com a ideia de um estudo preliminar.

Reforce-se que a pesquisa não pretende encontrar opiniões e sim percepções, e mais que isto, percepções sobre o ambiente que é cotidiano e que está arraigado ao modelo de vida do inquerido, sendo que:

A percepção do lugar, as sensações a ele relacionadas e a avaliação do ambiente como poluído ou não são fatores vinculados aos valores locais. (ANTUNES et al., 2014).

A pesquisa foi realizada com 40 pessoas domiciliadas próximas ao Rio Carahá, escolhidas aleatoriamente por meio de pesquisa via o motor de busca Google. Após contato prévio por telefone com os indivíduos selecionados, foram remetidos, por WhatsApp, os questionários criados por meio do SurveyMonkey, sendo que das 40 pessoas acionadas, 28 responderam o instrumento.

O questionário continha dois questionamentos no formato 'falso ou verdadeiro' e seis perguntas objetivas, ou seja, com múltiplas escolhas para resposta. O primeiro quesito do formulário era a assertiva, 'existe destino correto do esgoto na sua rua' a qual $82,14 \%$ dos inqueridos atribuíram ser falsa, bem demonstrando que os entrevistados têm consciência do problema de saneamento, ou da falta dele. Confirmando o fato, a segunda assertiva testada, 'o Carahá não é um rio e sim um canal de esgoto', obteve como resposta a opção 'verdadeiro' de impressionantes, 92,85\% dos arguidos.

A primeira pergunta com múltipla escolha de resposta tratava das enchentes recorrentes na cidade, para ela $42,85 \%$ dos entrevistados julgam que o lixo é sua principal causa, sendo que vale destacar que somente $10,71 \%$ dos respondentes atribuem o problema a falhas ou inoperância de órgãos públicos. Sobre o quesito cabe alertar que em diversos pontos do Rio Carahá há concentração massiva de lixo o que, muito provavelmente, como percepção, é atribuído a hábitos da população e não ao descaso ou incapacidade do setor público.

Na pergunta seguinte, quase a totalidade dos inqueridos, $96,42 \%$, reconhecem a existência dos projetos de tratamento de esgoto de Araucária e Ponte Grande, entretanto somente $21,42 \%$ dos entrevistados acreditam que terão algum benefício deles decorrentes. Aqui cabe nova explicação, pois o quesito indicava em uma das alternativas de resposta a palavra 'benefício' sem explicitar se tal benefício 
seria direto ou indireto. Além disso, conhecer os projetos dos dois complexos, não implica necessariamente em compreender seus benefícios para a cidade.

Sobre os maiores problemas decorrentes da poluição do Rio Carahá, 57,14\% dos entrevistados apontaram o 'mau cheiro', sendo que apenas 3,57\% indicaram 'indisponibilidade do recurso água' como principal dano. O baixíssimo número de respostas no item sobre a água do rio como um recurso em si mesmo, corrobora a percepção dos residentes de que o Carahá é um canal de esgoto e não um rio.

Sobre a atuação da Secretaria Municipal de Águas e Saneamento (Semasa) na política local de saneamento, $21,42 \%$ dos inqueridos se declararam satisfeitos e $32,14 \%$ insatisfeitos, enquanto $14,28 \%$ se dizem indiferentes ou não ter opinião e outros 14,28\% afirmam estar decepcionados. Já 17,85\% dos entrevistados disseram não ter informações suficientes para opinar.

Se somarmos o total de respostas de 'insatisfeitos' como os 'decepcionados' verificaremos que quase a metade dos entrevistados $(46,42 \%)$ veem falhas da administração municipal na área de saneamento. Entretanto, talvez mais grave que esse contingente de respostas negativas seja o fato de que $17,85 \%$ dos consultados não construírem percepção alguma sobre as políticas públicas de saneamento, potencialmente indicando que para esses indivíduos inexiste ação governamental, ao menos, para o Rio Carahá e, talvez, que sua poluição seja compreendida como irreversível.

\section{CONSIDERAÇÕES FINAIS}

Claro está que a pesquisa exploratória realizada não é conclusiva. Nenhum de seus dados podem ser considerados como como verdades comprováveis e, nem mesmo, dela pode-se inferir a percepção global dos munícipes sobre o objeto estudado. Reiteramos que o objetivo de nosso levantamento exploratório foi, exclusivamente, o de realizar um diagnóstico para nortear a elaboração futura de pesquisa mais ampla e abrangente.

De toda sorte, apuramos alguns indicativos sobre o conhecimento retido pelo munícipe de Lages quanto as políticas públicas municipais na esfera do saneamento e, mormente, quanto a imagem do Carahá como um rio degradado. A pesquisa exploratória chama também atenção sobre a pouca compreensão relativa ao volume e ao destino dos efluentes lançados no Rio Carahá, principalmente, sobre a possibilidade de ações de saneamento que permitam o estabelecimento de padrões mínimos de qualidade ou, se preferirmos de salubridade da água que corre no leito do Carahá.

O estudo preliminar também demonstra que os residentes no entorno do Carahá desconhecem os efeitos dos investimentos que vem sendo promovidos pela prefeitura para tratamento de esgoto, o que certamente pode ser revertido por um maior esforço dos órgãos públicos em comunicar os impactos coletivos de tais iniciativas, as quais na percepção aparente dos entrevistados, atende somente a certas regiões do município.

Seja como for, a pesquisa ora encerrada possibilitou a compressão de fatores que constituem a percepção local sobre política pública de saneamento, permitindo e elaboração de outros estudos visando identificar a percepção mais abrangente do lageano e como ela pode ser utilizada como ferramenta de apoio 
para o planejamento público (ou situacional), tendo claro que se o ambiente muda, as percepções dos sujeitos também mudam.

\section{REFERÊNCIAS}

ANTUNES, C.; BITTENCOURT, S.; RECH, T; OLIVEIRA, A.. Qualidade das águas e percepção de moradores sobre um rio urbano. Revista Brasileira de Ciências Ambientais, v.32, p.75-87, 2014.

CASARIN, H.; CASARINI, S.. Pesquisa Científica: da teoria à pratica. Curitiba: Intersaberes, 2012.

COELHO, Y.; LUCAS, F. C.; SARMENTO, P.. Percepção Ambiental e Mineração de Agregados: O Olhar da População Urbano-Rural de Ourém, Pará, Brasil. Desenvolvimento e Meio Ambiente, v.53, p.38-60, 2020. DOI: http://doi.org/10.5380/dma.v53i0.60771

DETRAN/SC - Departamento Estadual de Trânsito de Santa Catarina. Frota de Veículos por Município (mensal). Florianópolis: DENTRAN/SC, 2018.

\section{DIEHL, A.; TATIM, D.. Pesquisa em Ciências Sociais}

Aplicadas: métodos e técnicas. São Paulo: Prentice Hall, 2004.

GARCIA, F.. As transformações de uma cidade: a 'vilota rude' que se tornou 'Administração Municipal Modelo': o caso de Lages/SC. Revista Santa Catarina em História, v.11, n.1, p. 833, 2017.

GIL, A. C.. Como elaborar projetos de pesquisa. São Paulo: Atlas, 2008.

HUERTAS, F.. O método PES: entrevista com Matus. Campinas: Fundap, 1996.

IBGE. Instituto Brasileiro de Geografia e Estatística. Censo Demográfico de 2010. Rio de Janeiro: IBGE, 2010.
IBGE. Instituto Brasileiro de Geografia e Estatística. Cidade@. Rio de Janeiro: IBGE, 2016.

MARTINS, R. D. A.; CALDAS, E. L.. Uma análise comparada de experiências de desenvolvimento econômico local no Brasil. Revista Brasileira de Gestão e Desenvolvimento Regional, v.5, n.3, p.70-93, 2009.

QUINATTO, J.; ZAMBELLI, N. L. N.; SOUZA, D. H.; RAFAELI NETO, S. L.; CARDOSO, J. T.; SKORONSKI, E.. Avaliação da qualidade da água de um rio urbano utilizando o conceito de carga de poluentes: o caso do Rio Carahá (Lages, Brasil). Revista Ambiente e Água, v.14, n.1, 2019. DoI: http://doi.org/10.4136/ambi-agua.2252

RAFAELI NETO, S.; RICARDO, G. S.; MENDES, C.; CUNHA, M.. Modelagem Hidráulica dos Eventos de Inundações em Lages (SC). In: CONGRESSO BRASILEIRO DE GESTÃO AMBIENTAL, 6. Anais. Porto Alegre, 2015.

RANGEL, R.; PALMISANO, A.; TONON, D. H. P.; RANGEL, N. A. R.. Percepções dos Residentes em São Bento do Sul (SC) sobre as Possibilidades de Desenvolvimento do Município. Desenvolvimento em Questão, v.18, p.254-267, 2020. DOI: http://doi.org/10.21527/2237-6453.2020.50.254-267

SILVA, F. G.. Subjetividade, individualidade, personalidade e identidade: concepções a partir da psicologia históricocultural. Psicologia da Educação, n.28, p.169-195, 2009.

TIVES, A.. Em três anos a Semasa investe mais de $\mathbf{R} \mathbf{3 0}$ milhões em melhorias das redes de água e esgoto. 2019.

A CBPC - Companhia Brasileira de Produção Científica (CNPJ: 11.221.422/0001-03) detém os direitos materiais desta publicação. Os direitos referem-se à publicação do trabalho em qualquer parte do mundo, incluindo os direitos às renovações, expansões e disseminações da contribuição, bem como outros direitos subsidiários. Todos os trabalhos publicados eletronicamente poderão posteriormente ser publicados em coletâneas impressas sob coordenação da Sustenere Publishing, da Companhia Brasileira de Produção Científica e seus parceiros autorizados. Os (as) autores (as) preservam os direitos autorais, mas não têm permissão para a publicação da contribuição em outro meio, impresso ou digital, em português ou em tradução. 